\title{
Evaluation of Hepatic Mitochondria and Hematological Parameters in Zidovudine-Treated $\mathrm{B6C3F}_{1}$ Mice
}

\author{
Varsha G. Desai, ${ }^{1}$ Taewon Lee, ${ }^{2}$ Carrie L. Moland, ${ }^{1}$ William S. Branham, ${ }^{1}$ \\ Roberta A. Mittelstaedt, ${ }^{3}$ Sherry M. Lewis, ${ }^{4}$ Julian E. A. Leakey, ${ }^{4}$ and James C. Fuscoe ${ }^{1}$ \\ ${ }^{1}$ Division of Systems Biology, Center for Functional Genomics, U.S. FDA/National Center for Toxicological Research, \\ 3900 NCTR Road, Jefferson, AR 72079, USA \\ ${ }^{2}$ Department of Information and Mathematics, Korea University, Jochiwon, Chungnam 339-700, Republic of Korea \\ ${ }^{3}$ Division of Genetic and Molecular Toxicology, U.S. FDA/National Center for Toxicological Research, 3900 NCTR Road, \\ Jefferson, AR 72079, USA \\ ${ }^{4}$ Office of Scientific Coordination, U.S. FDA/National Center for Toxicological Research, 3900 NCTR Road, Jefferson, AR 72079, USA
}

Correspondence should be addressed to Varsha G. Desai, varsha.desai@fda.hhs.gov

Received 28 November 2011; Accepted 12 January 2012

Academic Editor: Robert R. Redfield

Copyright ( $) 2012$ Varsha G. Desai et al. This is an open access article distributed under the Creative Commons Attribution License, which permits unrestricted use, distribution, and reproduction in any medium, provided the original work is properly cited.

The effects of 12-week exposure to zidovudine (AZT) at 400, 500, and $600 \mathrm{mg} / \mathrm{kg} / \mathrm{d}$ were examined on expression of 542 mitochondria-related genes and mitochondrial DNA (mtDNA) copy number in the liver of male and female $\mathrm{B}_{6} \mathrm{C}_{3} \mathrm{~F}_{1}$ mice to understand mitochondrial role in sex-related differences in development of lactic acidosis. Plasma lactate levels and hematologic parameters were also examined. Results indicated increased red blood cell (RBC) count in vehicle-treated controls, whereas a dose-related decline in the RBC count was noted in AZT-treated mice compared to the basal levels before treatments began. These decreases were associated with significant dose-related increases in mean corpuscular volume and mean corpuscular hemoglobin levels. This effect was greater in AZT-treated females compared to males. In both sexes, 12-week AZT or vehicle exposure significantly reduced plasma lactate levels compared to the basal levels. Results also showed modest, but significant, changes in the expression of genes associated with apoptosis and lipid metabolism at $600 \mathrm{mg} / \mathrm{kg} / \mathrm{d}$ AZT. Neither drug nor sex influenced hepatic mtDNA copy number. Altogether, 12-week AZT exposure as high as $600 \mathrm{mg} / \mathrm{kg} / \mathrm{d}$ did not impair hepatic mitochondria or induce lactic acidosis in $\mathrm{B}_{6} \mathrm{C} 3 \mathrm{~F}_{1}$ mice. However, AZT-mediated hematologic toxicity appeared to be greater in females compared to males.

\section{Introduction}

The use of nucleoside reverse transcriptase inhibitors (NRTIs) in treatment of HIV-1 infections has been associated with a wide range of severe side effects, including lactic acidosis, hepatotoxicity, pancreatitis, lipodystrophy, neuropathy, and hematotoxicity [1]. In addition, sex-related differences in the frequency and severity of NRTI-related adverse effects have been reported. It has been shown that women are less likely than men to tolerate NRTI therapy [2] and also are at higher risk for developing NRTI-related toxicities [3]. Possible risk factors for sex-related differences in NRTI-induced toxicities include differences in body mass index, sex hormones, activities of kinases, drug-metabolizing enzymes, and the transport and excretion of the drug $[4,5]$.
Nonetheless, the molecular basis for an increased risk of developing NRTI-induced toxicity in HIV-1-infected women still remains unclear.

The majority of NRTI-related complications are believed to be due to altered mitochondrial function caused by phosphorylated metabolites of NRTIs that can inhibit DNA polymerase gamma and/or result in mtDNA chain termination $[6,7]$. DNA polymerase gamma is the mitochondria-specific polymerase required for replication and repair of the mtDNA that encodes critical proteins for energy production by oxidative phosphorylation. Inhibition of DNA polymerase gamma and/or damage to mtDNA by NRTIs would alter energy production, consequently impairing cellular and mitochondrial function. Inhibition of DNA polymerase gamma by NRTIs leading to the depletion of mtDNA levels has been 
reported $[8,9]$. Several studies, however, have also shown that NRTIs, such as zidovudine (AZT), can impair mitochondrial function independent of its effect on DNA polymerase gamma. This drug can affect other cellular targets including proteins involved in mitochondrial bioenergetics $[10,11]$, various metabolic pathways, and mitochondrial membrane transporters $[12,13]$.

One of the established measures of impaired mitochondrial energy production is higher blood lactate levels, which ultimately could lead to a life-threatening condition called lactic acidosis. Although rare, lactic acidosis is considered one of the most serious complications of NRTI therapy. It poses a major health concern in HIV-1-infected women, especially pregnant women, who are at greater risk of developing this adverse event compared to men $[14,15]$. Thus, there is evidence that mitochondrial dysfunction is involved in NRTI-mediated side effects. However, the association between altered mitochondrial function and sex-based differences in NRTI-induced adverse events, in particular, lactic acidosis, has not been established.

Bearing in mind that higher plasma lactate levels have been associated with mitochondrial dysfunction and that sex-related differences exist in the respiratory/oxidative potential of hepatic mitochondria [16], understanding mitochondrial activity during NRTI exposure will be critical to gain important insights into the role of mitochondria in sex-related differences in the development of hyperlactataemia/lactic acidosis. To address this, we examined the expression levels of 542 mitochondria-related genes and relative mtDNA copy number in the liver of male and female $\mathrm{B}_{6} \mathrm{C}_{3} \mathrm{~F}_{1}$ mice treated with AZT, a principal antiretroviral drug used in combination regimens to treat HIV-1 infection. Plasma lactate levels were measured during AZT treatment to determine possible hyperlactataemia. Based on clinical studies that demonstrate AZT-related hematologic toxicity [17, 18], the RBC count, hemoglobin $(\mathrm{Hb})$, mean corpuscular volume (MCV), and mean corpuscular hemoglobin $(\mathrm{MCH})$ levels were also measured during AZT treatments in these mice.

\section{Materials and Methods}

2.1. Animal Husbandry. Male and female $\mathrm{B}_{6} \mathrm{C}_{3} \mathrm{~F}_{1}$ mice were obtained from the breeding colony at the National Center for Toxicological Research (NCTR). Mice were raised in a pathogen-free environment and treated according to Institutional Animal Care and Use Committee guidelines. Animals were housed two per polycarbonate cage with hardwood chip bedding and maintained at $23^{\circ} \mathrm{C}$ with a relative humidity of 50\%. The animals were conditioned to a $12 \mathrm{hr}$ light/12 hr dark cycle with lights on from 0600 to $1800 \mathrm{hr}$ daily and were given autoclaved NIH-31 diet and filtered tap water ad libitum.

2.2. Animal Treatments. Beginning at 8 weeks of age, mice were administered AZT (Cipla, Mumbai, India) by gavage at $0,400,500$, and $600 \mathrm{mg} / \mathrm{kg}$ body weight/day for 12 weeks. McTween, which is a mixture of $0.2 \%$ methylcellulose and
$0.1 \%$ polysorbate 80 , was used as the vehicle. The AZT doses of 400,500 , and $600 \mathrm{mg} / \mathrm{kg} / \mathrm{d}$ were selected based on a prior study that showed altered expression levels of hepatic mitochondria-related genes at $240 \mathrm{mg} / \mathrm{kg}$ AZT in C3B6 $\mathrm{F}_{1} \operatorname{trp} 53$ transgenic mice [13]. Also, the AZT doses of the current study were selected to severely impair mitochondrial function, but not high enough to be fatal to the animal. The human therapeutic dose for AZT is $10 \mathrm{mg} / \mathrm{kg}$ body weight/day [19]. On the basis of body surface area $\left(\mathrm{mg} / \mathrm{m}^{2}\right)$, the mice on the current study were exposed to $3.2,4.0$, and 4.8 times the clinical therapeutic dose, respectively. Control mice were administered McTween by gavage. Each group consisted of six animals. Animals were weighed and monitored daily for abnormal clinical signs.

2.3. Tissue Collection. Blood was collected from mice before treatment began and also during the course of the treatment. Blood was collected from the saphenous vein of each animal and a portion of the blood was transferred into Microtainer tubes containing sodium fluoride and potassium oxalate (BD Biosciences, Franklin Lakes, NJ) for the measurements of lactate levels. The remaining blood was transferred into Microtainer tubes containing EDTA (BD Biosciences) for the measurements of hematologic parameters ( $\mathrm{RBC}$ count, $\mathrm{Hb}$, $\mathrm{MCV}, \mathrm{MCH}$ ). Blood samples collected for lactate measurements were immediately centrifuged at $1000 \times \mathrm{g}$ for $10 \mathrm{~min}-$ utes at room temperature to separate the plasma. Following 12 -week treatment, animals were humanely euthanized by excessive inhalation of gaseous $\mathrm{CO}_{2} 24 \mathrm{hr}$ after the last dose. To avoid possible adverse effects of $\mathrm{CO}_{2}$ asphyxiation on lactate levels, 30 minutes prior to euthanization, blood was collected from the saphenous vein for lactate measurements. Immediately following euthanasia, the median lobe of the liver was removed, minced in RNA later (Ambion, Austin, TX) and stored at $-20^{\circ} \mathrm{C}$ until expression analysis of mitochondria-related genes. Another piece of the liver was immediately frozen in liquid nitrogen and stored at $-80^{\circ} \mathrm{C}$ until measurements of mtDNA copy number.

2.4. Measurement of Expression Levels of Mitochondria-Related Genes Using the Mouse MitoChip. Extraction of total RNA from liver tissues, reverse transcription to cDNA and labeling with fluorescent cyanine dyes, hybridization of labeled cDNAs on MitoChips, washing and scanning of hybridized arrays were as described previously [20]. In brief, total RNA was isolated from liver tissues using Qiagen RNeasy mini kit (Qiagen, Valencia, CA) followed by quantification of extracted RNA on a spectrophotometer at $260 \mathrm{~nm}$ and $280 \mathrm{~nm}$. The quality of RNA samples was further determined using the RNA 6000 LabChip and Agilent 2100 Bioanalyzer (Agilent Technologies, Palo Alto, CA) and RNA samples with RNA integration number higher than 8.5 were used for microarray experiment. DNase-treated RNA samples were reverse transcribed using random hexamer primers (Invitrogen, Carlsbad, CA) and SuperScript II reverse transcriptase (Invitrogen) in the presence of reverse transcription labeling mixture containing dNTPs (Invitrogen) and aminoallyl-dUTP (aa-dUTP, Sigma, St. Louis, MO). 
Following purification, the aminoallyl-cDNA pellet was coupled with fluorescent cyanine dyes (Cy3 or Cy5, Amersham Pharmacia, Piscataway, NJ). Stratagene Universal Mouse Reference RNA (UMRR, Agilent Technologies, Cedar Creek, TX) was used as a reference RNA. Experimental samples and UMRR were labeled with Cy5 and Cy3, respectively. Each Cy5-labeled sample was cohybridized with Cy3-labeled UMRR on a MitoChip arrays and hybridized at $42^{\circ} \mathrm{C}$ for 18 hours in a water bath. This was followed by washing of arrays with sodium chloride sodium citrate buffer containing different concentrations of sodium dodecyl sulphate prewarmed at $30^{\circ} \mathrm{C}$. MitoChip arrays were printed at the National Center for Toxicological Research. Each slide consisted of two microarrays. Following hybridization, arrays were scanned with a GenePix 4000B scanner (Axon Instruments, Union City, CA) at $10 \mu \mathrm{m}$ resolution.

The expression level of each gene for a sample was estimated by the average of the $\log _{2}$ ratio of the fluorescence of $\mathrm{Cy} 5$ (the sample) relative to the fluorescence of $\mathrm{Cy} 3$ (the reference) from the two arrays on the slide. Each array consisted of 9 housekeeping genes as positive controls and 9 Arabidopsis genes as negative controls. The expression level of control genes (housekeeping genes and Arabidopsis genes) for a sample was averaged and used as a covariate to normalize the expression data. A relative fold-change in the expression level of a gene was calculated as the ratio of the average expression of treated samples to untreated controls. Differences associated with treatment, sex, and their interactions were estimated under a fixed effect linear model with adjustment for batch effects and normalizing covariates using the Generalized Linear Model procedure of SAS 9.1.3. The results were further classified into different Gene Ontologies using the database from Mouse Genome Informatics (http://www.informatics.jax.org/). Overall treatment effects on the groups of genes (molecular function/biological process) were tested using a modified meta-analysis method for combining correlated $P$ values [21].

\subsection{Isolation of DNA and Measurement of Relative mtDNA} Copy Number in the Liver. Isolation of DNA and measurement of relative mtDNA copy number in the liver were as described previously [22]. In brief, approximately $20 \mathrm{mg}$ of liver tissue was homogenized in phosphate buffered saline (PBS) containing ФX174 DNA (replicative form; NE Biolabs, Beverly, MA) as a reference DNA. To this, RNaceIt (Agilent Technologies, Santa Clara, CA), and phosphorylase $\mathrm{b}$ from rabbit muscle (Sigma-Aldrich, St. Louis, MO) were added, followed by the addition of PBS without phage DNA to a final volume of $500 \mu \mathrm{L}$ before incubation at $37^{\circ} \mathrm{C}$ for 2 hours. This was followed by addition of $90 \mu \mathrm{L}$ of a digestion buffer containing $180 \mathrm{mM}$ TRIS-HCl $(\mathrm{pH}$ $8.0), 60 \mathrm{mM}$ sodium EDTA, $10 \%$ SDS, and $1.2 \mathrm{mg}$ proteinase $\mathrm{K}$ (Qiagen, Valencia, CA) and tubes were incubated at $55^{\circ} \mathrm{C}$ overnight. This digest was further incubated at $95^{\circ} \mathrm{C}$ for 15 minutes, cooled to room temperature, and briefly centrifuged. Isolation of DNA from the digest was performed using TRI Reagent LS (Sigma-Aldrich) according to manufacturer's instructions. The resulting DNA pellets were dis- solved in $75 \mu \mathrm{L}$ of $8 \mathrm{mM} \mathrm{NaOH}$, and the quality and quantity of the DNA was assessed with an ND-1000 spectrophotometer (NanoDrop, Wilmington, DE).

Relative mtDNA copy number was determined by a modification of the quantitative real-time PCR [TaqMan (Applied Biosystems), Foster City, CA)] assay method developed by Myers and colleagues [22]. Samples were analyzed on an ABI 7500 Sequence Detection System (Applied Biosystems) using TaqMan MGB probes designed for sequences specific to a region of the mouse mtDNA D-loop and the $\Phi X 174$ DNA reference. A calibrator sample containing equal ratios of D-loop and ФX174 sequence was run on every plate used for quantitative-PCR analysis to allow all of the samples to be expressed as an $\mathrm{n}$-fold difference relative to the calibrator using SDS software v1.1 (Applied Biosystems) and the comparative $C_{t}$ method [23]. Two-way ANOVA was performed to determine AZT- and sex-related effects on relative mtDNA copy number.

2.6. Measurements of Plasma Lactate Level and Hematological Parameters. Lactate measurements were carried out using a lactate kit according to the manufacturer's instructions (Trinity Biotech, Ireland) on a COBAS Mira Plus automated spectrophotometer (Roche, Nutley, NJ). Statistical significance of dose-related changes in lactate levels for each sex was tested under a fixed effects linear model with a covariate of dose levels. Statistical significance of sex-related differences in lactate levels between 0 - and 12-week was tested by $t$ tests, and $P$-values less than 0.05 were considered significant. During the course of the treatments (0-11-week), the RBC count, $\mathrm{Hb}$ content, $\mathrm{MCV}$, and $\mathrm{MCH}$ were measured every week on a hematology analyzer, the PENTRA $60 \mathrm{C}+$ (Horiba $A B X$, France), using ABX reagents to determine anemia. Statistical significance of dose-related changes for each sex and sex-related differences in hematological parameters between 0 - and 11-week was evaluated by $t$-tests, and $P$ values less than 0.05 were considered significant. For the estimation of differences and the statistical analysis, a Generalized Linear Model of SAS 9.1.3 was used.

\section{Results and Discussion}

The present study evaluated liver mitochondria in AZTtreated $\mathrm{B} 6 \mathrm{C} 3 \mathrm{~F}_{1}$ mice to understand the role of mitochondria in sex-related differences in the development of lactic acidosis. Both male and female $\mathrm{B}_{6} \mathrm{C} 3 \mathrm{~F}_{1}$ mice were treated with 400,500 , or $600 \mathrm{mg} / \mathrm{kg} / \mathrm{d} \mathrm{AZT}$ at doses predicted to severely alter mitochondrial function leading to hyperlactataemia/lactic acidosis. Despite the relatively high doses of AZT, there was no increase in plasma lactate levels in these mice. However, other classical parameters of clinical toxicity observed with AZT were altered and in a sex-related manner.

During the course of AZT treatments, hematological parameters were measured through 11 weeks of treatment to monitor possible anemia in these mice. Following 11-week exposure, significant changes in hematological parameters were found at all AZT exposures (Table 1). An AZT-related decline in the RBC count was observed in both sexes. The 
decreases in the RBC counts were $13 \%, 11 \%$, and $8 \%$ in male AZT-treated mice at 400, 500, and $600 \mathrm{mg} / \mathrm{kg} / \mathrm{d}$, respectively, whereas the decreases were between $16-26 \%$ in female mice compared to 0 -week (Table 1), and these declines were significant at 400 and $600 \mathrm{mg} / \mathrm{kg} / \mathrm{d}$ AZT only in female mice. This may indicate a greater influence of AZT on the RBC count in female mice than males and this sex-related difference was significant at the $500 \mathrm{mg} / \mathrm{kg} / \mathrm{d}$ dose. The occurrence of anemia characterized by reduced $\mathrm{Hb}$ levels has been reported in HIV-1 infected patients on NRTI therapies $[24,25]$. In the present study, however, the $\mathrm{Hb}$ contents were not significantly altered despite the decline in RBC counts at all AZT doses (Table 1). On the other hand, small increases in $\mathrm{RBC}$ and $\mathrm{Hb}$ contents were observed in male and female mice following 11-week vehicle treatment compared to 0-week, and the increase was significant only in RBC counts in male mice (Table 1). At present, a likely mechanism underlying significant findings in vehicle-treated mice is unclear. More experiments need to be conducted to evaluate these changes.

In addition to the decline in RBC counts, AZT-treated mice showed significant dose-related increases in MCV and MCH levels (Table 1). Male mice treated with 400, 500, or $600 \mathrm{mg} / \mathrm{kg} / \mathrm{d}$ AZT had a 22\%, 22\%, or 29\% increase, respectively, in MCV at 11-week compared to 0-week. In AZTtreated female mice, the MCV levels were increased by $29 \%, 29 \%$, and $36 \%$ following 11 -week treatment with 400, 500, and $600 \mathrm{mg} / \mathrm{kg} / \mathrm{d}$ AZT, respectively. In both AZTtreated male and female mice, these changes in MCV were associated with increases in $\mathrm{MCH}$ levels. While male mice had $15 \%, 17 \%$, and $22 \%$ increases in $\mathrm{MCH}$ at 400,500 , and $600 \mathrm{mg} / \mathrm{kg} / \mathrm{d}$ AZT, respectively, female mice showed $19 \%, 20 \%$, and $27 \%$ increases at 400,500 , and $600 \mathrm{mg} / \mathrm{kg} / \mathrm{d}$ AZT, respectively. Thus, as for the RBC counts, a greater AZT influence was seen in female mice, and this sex-related difference was significant at 400 and $500 \mathrm{mg} / \mathrm{kg} / \mathrm{d}$ doses for both MCV and MCH levels but not at $600 \mathrm{mg} / \mathrm{kg} / \mathrm{d}$ (Table 1). It is possible that beyond a certain threshold high concentration of AZT may overcome the genomic differences between sexes.

The MCV represents the average size of the RBC, and $\mathrm{MCH}$ indicates the amount of $\mathrm{Hb}$ in each $\mathrm{RBC}$. Dose-related increases in MCV and MCH levels in AZT-treated mice might suggest a compensatory mechanism in response to a dose-related decline in the RBC count, which may further explain nonsignificant changes observed in $\mathrm{Hb}$ contents in these mice. Corroborating these findings are animal studies that reported hematologic toxicity as evidenced by the decreased erythrocyte count, higher MCV and MCH levels, and increased incidence of macrocytic anemia during AZT exposure [26-28]. The increased MCV indicates larger than normal RBCs, which are known as macrocytes. Although $\mathrm{Hb}$ levels were not altered in AZT-treated mice, higher MCV and $\mathrm{MCH}$ levels in response to decreased $\mathrm{RBC}$ count may indicate the initial phase of macrocytic anemia in these mice. Interestingly, a sex effect was seen in both MCV and $\mathrm{MCH}$ levels, where AZT-treated female mice had greater increases than their male counterparts and these increases were significant at 400 and $500 \mathrm{mg} / \mathrm{kg} / \mathrm{d}$ doses. Altogether, these findings suggest the occurrence of hematotoxicity in
AZT-treated $\mathrm{B}_{6} \mathrm{C} 3 \mathrm{~F}_{1}$ mice at all doses and this toxicity appeared to be greater in female mice than in males.

Although an increase in plasma lactate levels was anticipated upon AZT exposure, 12-week dosing with AZT significantly reduced plasma lactate levels in both male and female mice compared to the levels before treatment began (Table 2). The decreases in lactate levels showed no AZT dose response and were also found in animals treated with vehicle alone. The mechanism(s) underlying these decreases in lactate levels is unclear. Control and treated mice were given McTween, which is a commonly used emulsifying agent in drug treatments of laboratory animals in toxicology studies. However, changes in lactate levels in vehicle-treated mice similar to those seen in AZT-treated mice suggest a likely influence of McTween on lactate levels rather than the AZT. In future studies, the use of sterile water as the drug vehicle may help avoid this possible confounding effect.

In toxicological studies, increased lactate levels have been related to mitochondrial dysfunction in various druginduced toxicities $[29,30]$. In the present study, however, none of the AZT doses significantly altered the transcription levels of genes involved in mitochondrial energy production in the liver of $\mathrm{B}_{6} \mathrm{C} 3 \mathrm{~F}_{1}$ mice. In view of these findings, lack of increase in plasma lactate levels in AZT-treated mice is not surprising. A moderate, but significant effect of AZT was evident only at $600 \mathrm{mg} / \mathrm{kg} / \mathrm{d}$ on the expression levels of genes associated with apoptosis and lipid metabolism (Table 3). Expression levels of proapoptotic genes (Bax, Bbc3, and Bnip3) were significantly increased in the liver. Bbc3 induces a conformational change in Bax, which is essential for apoptotic events mediated through the intrinsic pathway [31], whereas Bnip3 induces apoptosis by opening the mitochondrial permeability pore with consequential membrane depolarization [32]. Although immunohistochemical evaluation was not performed in the liver tissues to verify apoptotic changes, increased expression of proapoptotic genes may indicate a cellular response to AZT exposure, probably to remove damaged cells. Supporting this interpretation are in vitro and in vivo studies that reported increased apoptosis during exposures to antiretroviral drugs, including AZT $[33,34]$.

AZT-treated mice also exhibited differential expression of genes involved in lipid metabolism at $600 \mathrm{mg} / \mathrm{kg} / \mathrm{d}$ dose. Increased transcriptional level of acyl-coenzyme A synthase (Acsl3) was associated with decreased expression levels of acyl-coenzyme A dehydrogenases for short-chain (Acads), short/branched chain (Acadsb), and long-chain fatty acids (Acadl). Acsl3 is required for the activation of long-chain fatty acids, whereas Acads, Acadsb, and Acadl are involved in the initial step of fatty acid $\beta$-oxidation. Decreases in the expression levels of acyl-coenzyme A dehydrogenases in AZT-treated mice were modest; however, in long-term therapies, such changes may, in part, contribute to fat accumulation in the liver. Hepatic steatosis, a condition characterized by excess fat accumulation within liver cells, has been indicated as one of the complications of antiretroviral therapy in HIV-1 infected patients [35]. Overall, the effect of AZT on hepatic mitochondria was minimal in $\mathrm{B}_{6} \mathrm{C} 3 \mathrm{~F}_{1}$ mice. This was further supported by nonsignificant changes in mtDNA 


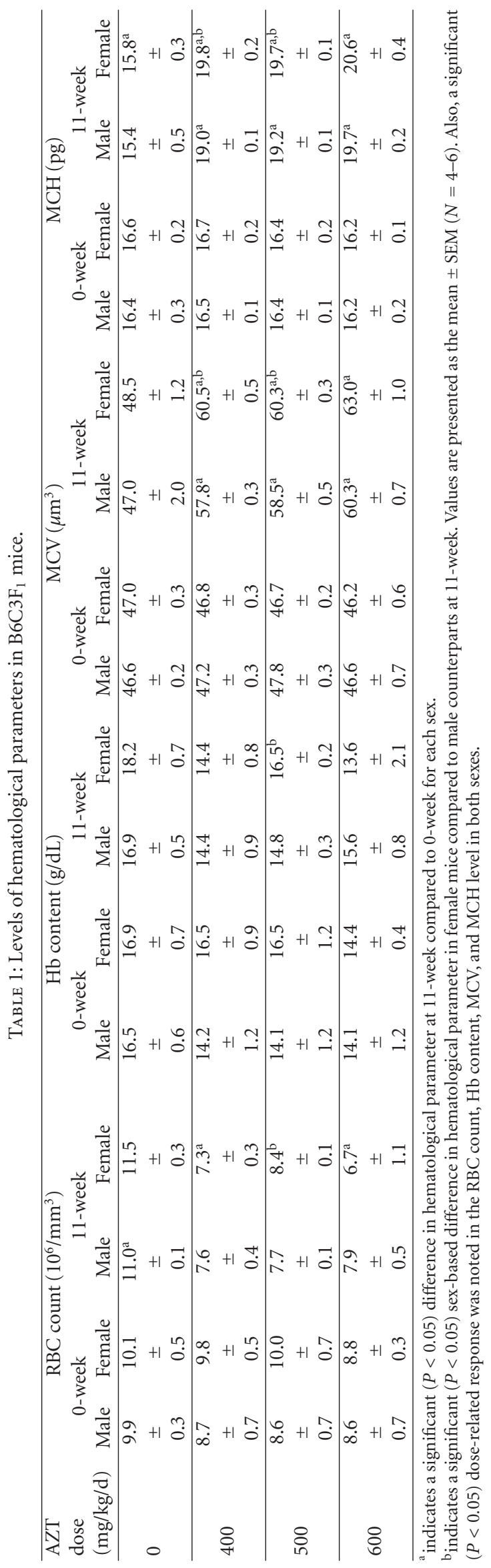




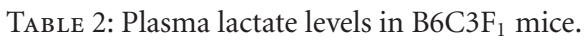

\begin{tabular}{|c|c|c|c|c|}
\hline \multirow{3}{*}{ AZT dose $(\mathrm{mg} / \mathrm{kg} / \mathrm{d})$} & \multicolumn{4}{|c|}{ Plasma lactate level (mg/dL) } \\
\hline & \multicolumn{2}{|c|}{0 -week } & \multicolumn{2}{|c|}{ 12-week } \\
\hline & Male & Female & Male & Female \\
\hline 0 & $101.4 \pm 10.3$ & $126.5 \pm 15.4$ & $71.5 \pm 1.8^{\mathrm{a}}$ & $62.0 \pm 3.2^{\mathrm{a}, \mathrm{b}}$ \\
\hline 400 & $100.0 \pm 3.7$ & $92.6 \pm 9.2$ & $79.3 \pm 8.0^{\mathrm{a}}$ & $56.0 \pm 5.8^{\mathrm{a}, \mathrm{b}}$ \\
\hline 500 & $96.7 \pm 3.2$ & $87.5 \pm 2.2$ & $57.9 \pm 5.2^{\mathrm{a}}$ & $56.3 \pm 4.2^{\mathrm{a}}$ \\
\hline 600 & $92.6 \pm 4.2$ & $91.2 \pm 2.6$ & $65.7 \pm 4.3^{\mathrm{a}}$ & $52.7 \pm 2.3^{\mathrm{a}, \mathrm{b}}$ \\
\hline
\end{tabular}

andicates a significant $(P<0.05)$ difference in plasma lactate levels at 12 -week compared to 0 -week for each sex.

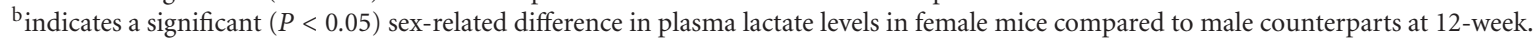

Values are presented as the mean $\pm \operatorname{SEM}(N=4)$.

TABLE 3: Effect of AZT ( $600 \mathrm{mg} / \mathrm{kg} / \mathrm{d})$ on the expression levels of genes in the liver of $\mathrm{B}_{6} \mathrm{C} 3 \mathrm{~F}_{1}$ mice.

\begin{tabular}{|c|c|c|c|}
\hline Gene description (gene symbol) & GenBank accession ID & FC & $P$ \\
\hline \multicolumn{4}{|l|}{ Apoptosis (18), $P=0.039$} \\
\hline Bcl2-associated X protein $(B a x)$ & NM_007527 & 1.143 & 0.020 \\
\hline Bcl2 binding component 3 (Bbc3) & NM_133234 & 1.065 & 0.032 \\
\hline Bcl2/adenovirus E1B 19 k Da-interacting protein 1, NIP3 (Bnip3) & NM_009760 & 1.159 & 0.041 \\
\hline \multicolumn{4}{|l|}{ Lipid metabolism (23), $P=0.046$} \\
\hline Acyl-Coenzyme A synthetase long-chain family member 3 (Acsl3) & AK012088 & 1.166 & 0.001 \\
\hline Acyl-Coenzyme A dehydrogenase, long-chain (Acadl) & NM_007381 & -1.159 & 0.025 \\
\hline Acyl-Coenzyme A dehydrogenase, short-chain (Acads) & NM_007383 & -1.142 & 0.022 \\
\hline Acyl-Coenzyme A dehydrogenase, short/branched chain (Acadsb) & NM_025826 & -1.225 & 0.011 \\
\hline \multicolumn{4}{|l|}{ Mitochondrial genes (13), $P=$ NS } \\
\hline NADH ubiquinone dehydrogenase, subunit $1(m t-N d 1)$ & AK018753 & 1.080 & 0.310 \\
\hline NADH ubiquinone dehydrogenase, subunit $2(m t-N d 2)$ & AU018363 & 1.080 & 0.280 \\
\hline NADH ubiquinone dehydrogenase, subunit 3 ( $m t-N d 3$ ) & J01420 & 1.021 & 0.724 \\
\hline NADH ubiquinone dehydrogenase, subunit 4 (mt-Nd4) & AB042809 & 1.018 & 0.827 \\
\hline NADH ubiquinone dehydrogenase, subunit 4L ( $m t-N d 4 l)$ & AA109866 & 1.048 & 0.526 \\
\hline NADH ubiquinone dehydrogenase, subunit 5 (mt-Nd5) & AU018713 & 1.050 & 0.564 \\
\hline NADH ubiquinone dehydrogenase, subunit 6 ( $m t-N d 6)$ & AA435281 & 1.081 & 0.144 \\
\hline Cytochrome b (mt-Cytb) & AU018811 & 1.013 & 0.861 \\
\hline Cytochrome c oxidase, subunit I ( $m t-C o 1)$ & AU018394 & 1.014 & 0.829 \\
\hline Cytochrome c oxidase, subunit II ( $m t$-Co2) & AU019143 & 1.054 & 0.449 \\
\hline Cytochrome c oxidase, subunit III ( $m t$-Co3) & AB042432 & 1.018 & 0.765 \\
\hline ATP synthase, subunit 6 (mt-ATP6) & AF093677 & 1.008 & 0.906 \\
\hline ATP synthase, subunit 8 ( $m t-A T P 8)$ & J01420 & 1.067 & 0.464 \\
\hline
\end{tabular}

The bold numbers in parentheses indicate number of genes evaluated for the molecular function. $P$ values in bold represent effect of AZT on the molecular function, which is a combined effect of AZT-related changes in expression levels of number of genes evaluated for the molecular function. FC indicates a relative fold change in mice treated with $600 \mathrm{mg} / \mathrm{kg} / \mathrm{d}$ AZT compared to vehicle-treated control mice. Negative values of fold changes indicate down-regulation of genes. Mitochondrial genes important in energy production, for which $600 \mathrm{mg} / \mathrm{kg} / \mathrm{d}$ AZT did not alter transcription, are also presented in the table. Sexrelated differences in the expression levels of mitochondria-related genes were not observed in liver of AZT-treated mice. NS: Not significant.

TABLe 4: Relative mitochondrial DNA (mtDNA) copy number in the livers of $\mathrm{B}_{6} \mathrm{C} 3 \mathrm{~F}_{1}$ mice.

\begin{tabular}{lcr}
\hline AZT dose $(\mathrm{mg} / \mathrm{kg} / \mathrm{d})$ & Male & B6C3F mice \\
\hline 0 & $12.02 \pm 4.87(N=6)$ & $8.46 \pm 1.51(N=6)$ \\
400 & $8.46 \pm 3.83(N=5)$ & $7.37 \pm 1.57(N=6)$ \\
500 & $18.69 \pm 8.26(N=6)$ & $8.95 \pm 1.29(N=6)$ \\
600 & $11.66 \pm 7.05(N=5)$ & $10.08 \pm 1.75(N=5)$ \\
\hline
\end{tabular}

The mtDNA copy number was based on quantitative real-time PCR measurements of D-loop concentration relative to the concentration of $\Phi$ X174RF added at a fixed concentration before DNA extraction. The numbers in parentheses indicate the number of animals in the group. Values are presented as the mean \pm SEM (Standard error of the mean). 
copy number in the livers of AZT-treated mice (Table 4). Expression levels of mtDNA-encoded genes critical in energy production also remained unaltered by AZT treatment (Table 3). In addition, AZT-treated mice did not show sexrelated differences in the expression levels of mitochondriarelated genes or mtDNA copy number in the liver. Sexbased differences in the expression levels were evident only in vehicle-treated controls: female mice showing higher expression levels compared to males, and these genes were associated with complexes I, III, and V of oxidative phosphorylation and the Krebs cycle (data not shown).

In contrast to the paucity of gene expression changes found in this investigation, a previous study from our laboratory using a different mouse model showed that the expression of 164 genes was significantly altered by AZT exposure [13]. The reasons for this dramatic difference may be attributed to differences in genotype, age, and exposure to AZT. In the previous study, a p53 haplodeficient mouse strain was used. The single functional copy of the p53 gene in this strain may allow cells with damaged mitochondria to survive, and thus express altered mitochondria-encoding genes, by partially inhibiting apoptosis. The ages of the mice in the two studies, as well as the duration of exposure, were also different with young animals being used in the prior study (exposed perinatally from gestation day 12 to 18 followed by continuation of same treatment from postnatal day 1 through 28 days of age) and adult animals (exposed from 8 weeks of age to 20 weeks of age) used in the present study. Further studies will be required to fully understand the possible influence of genotype and age on gene expression changes induced by AZT.

In conclusion, the AZT doses used in the present study, although as high as $600 \mathrm{mg} / \mathrm{kg} / \mathrm{d}$, did not induce hyperlactataemia/lactic acidosis in $\mathrm{B}_{6} \mathrm{C}_{3} \mathrm{~F}_{1}$ mice. This could be due to the absence of an AZT effect on hepatic mitochondria as evidenced by nonsignificant changes in the expression levels of mitochondria-related genes: in particular, genes associated with oxidative phosphorylation or the copy number of mtDNA. It is possible that higher doses of AZT and/or longer duration of AZT exposure may be necessary to significantly impair hepatic mitochondrial function in order to develop hyperlactataemia/lactic acidosis in $\mathrm{B}_{6} \mathrm{C}_{3} \mathrm{~F}_{1}$ mice. Alternatively, use of a more sensitive mouse model, such as the p53 haplodeficient mouse, may accelerate mitochondrial dysfunction and will provide better insights into the role of mitochondria in sex-associated differences in AZT-related adverse events. In $\mathrm{B}_{6} \mathrm{C} 3 \mathrm{~F}_{1}$ mice, AZT effect on mitochondria was limited to modest changes in the expression levels of genes associated with apoptosis and lipid metabolism and occurred only at the highest dose. A striking finding, however, was a sex-related difference in hematologic toxicity in AZT-treated mice: female mice exhibiting a greater response than males.

\section{Disclaimer}

The findings and conclusions in this paper are those of the authors and do not necessarily represent the views of the FDA.

\section{Acknowledgments}

This paper was funded by the Office of Women's Health/U.S. Food and Drug Administration and partly supported by the Food and Drug Administration/National Center for Toxicological Research, the National Institute for Environmental Health Sciences/National Toxicology Program Interagency Agreement (FDA no. 224-07-007) (NIH no. Y1ES1027). Also, the authors thank Drs. Mugimane Manjanatha and Syed Imam for their critical review of the paper.

\section{References}

[1] D. T. Dieterich, "Long-term complications of nucleoside reverse transcriptase inhibitor therapy," AIDS Reader, vol. 13, no. 4, pp. 176-187, 2003.

[2] J. S. Currier, C. Spino, J. Grimes et al., "Differences between women and men in adverse events and $\mathrm{CD} 4^{+}$responses to nucleoside analogue therapy for HIV infection," Journal of Acquired Immune Deficiency Syndromes, vol. 24, no. 4, pp. 316$324,2000$.

[3] I. Ofotokun and C. Pomeroy, "Sex differences in adverse reactions to antiretroviral drugs," Top HIV Med, vol. 11, no. 2, pp. 55-59, 2003.

[4] M. Gandhi, F. Aweeka, R. M. Greenblatt, and T. F. Blaschke, "Sex differences in pharmacokinetics and pharmacodynamics," Annual Review of Pharmacology and Toxicology, vol. 44, pp. 499-523, 2004.

[5] I. Ofotokun, "Sex differences in the pharmacologic effects of antiretroviral drugs: potential roles of drug transporters and phase 1 and 2 metabolizing enzymes," Topics in HIV Medicine, vol. 13, no. 2, pp. 79-83, 2005.

[6] H. Lee, J. Hanes, and K. A. Johnson, “Toxicity of nucleoside analogues used to treat AIDS and the selectivity of the mitochondrial DNA polymerase," Biochemistry, vol. 42, no. 50, pp. 14711-14719, 2003.

[7] J. J. Kohler and W. Lewis, "A brief overview of mechanisms of mitochondrial toxicity from NRTIs," Environmental and Molecular Mutagenesis, vol. 48, no. 3-4, pp. 166-172, 2007.

[8] C. L. Cherry, D. Nolan, I. R. James et al., "Tissue-specific associations between mitochondrial DNA levels and current treatment status in HIV-infected individuals," Journal of Acquired Immune Deficiency Syndromes, vol. 42, no. 4, pp. 435440, 2006.

[9] R. L. Divi, T. L. Einem, S. L. L. Fletcher et al., "Progressive mitochondrial compromise in brains and livers of primates exposed in utero to nucleoside reverse transcriptase inhibitors (NRTIs)," Toxicological Sciences, vol. 118, no. 1, pp. 191-201, 2010.

[10] M. Gerschenson, S. W. Erhart, C. Y. Paik et al., "Fetal mitochondrial heart and skeletal muscle damage in Erythrocebus patas monkeys exposed in utero to $3^{\prime}$-azido- $3^{\prime}$-deoxythymidine," AIDS Research and Human Retroviruses, vol. 16, no. 7, pp. 635-644, 2000.

[11] S. M. Torres, R. L. Divi, D. M. Walker et al., "In utero exposure of female CD-1 mice to AZT and/or 3TC: II. Persistence of functional alterations in cardiac tissue," Cardiovascular Toxicology, vol. 10, no. 2, pp. 87-99, 2010.

[12] K. C. Lund and K. B. Wallace, "Direct, DNA pol- $\gamma$-independent effects of nucleoside reverse transcriptase inhibitors on mitochondrial bioenergetics," Cardiovascular Toxicology, vol. 4, no. 3, pp. 217-228, 2004. 
[13] V. G. Desai, T. Lee, R. R. Delongchamp et al., "Nucleoside reverse transcriptase inhibitors (NRTIs)-induced expression profile of mitochondria-related genes in the mouse liver," $\mathrm{Mi}$ tochondrion, vol. 8, no. 2, pp. 181-195, 2008.

[14] R. Geddes, S. Knight, M. Y. S. Moosa, A. Reddi, K. Uebel, and H. Sunpath, "A high incidence of nucleoside reverse transcriptase inhibitor (NRTI)-induced lactic acidosis in HIVinfected patients in a South African context," South African Medical Journal, vol. 96, no. 8, pp. 722-724, 2006.

[15] C. W. Wester, O. A. Okezie, A. M. Thomas et al., "Higher-thanexpected rates of lactic acidosis among highly active antiretroviral therapy-treated women in Botswana: preliminary results from a large randomized clinical trial," Journal of Acquired Immune Deficiency Syndromes, vol. 46, no. 3, pp. 318-322, 2007.

[16] R. Justo, J. Boada, M. Frontera, J. Oliver, J. Bermúdez, and M. Gianotti, "Gender dimorphism in rat liver mitochondrial oxidative metabolism and biogenesis," American Journal of Physiology, vol. 289, no. 2, pp. C372-C378, 2005.

[17] G. Moyle, "Anaemia in persons with HIV infection: prognostic marker and contributor to morbidity," AIDS Reviews, vol. 4, no. 1, pp. 13-20, 2002.

[18] A. Sharma, R. Vora, M. Modi, A. Sharma, and Y. Marfatia, "Adverse effects of antiretroviral treatment," Indian Journal of Dermatology, Venereology and Leprology, vol. 74, no. 3, pp. 234-237, 2008.

[19] Center for Disease Control (CDC) and Prevention, Public Health Services Task Force. Recommendations for use of antiretroviral drugs in pregnant HIV-infected women for maternal health and interventions to reduce perinatal HIV-1 transmission in the United States, 2008, http://www.aidsinfo .nih.gov/guidelines/.

[20] V. G. Desai, T. Lee, R. R. Delongchamp et al., "Development of mitochondria-specific mouse oligonucleotide microarray and validation of data by real-time PCR," Mitochondrion, vol. 7, no. 5, pp. 322-329, 2007.

[21] R. Delongchamp, T. Lee, and C. Velasco, "A method for computing the overall statistical significance of a treatment effect among a group of genes," BMC Bioinformatics, vol. 7, supplement 2, article S11, 2006.

[22] M. B. Myers, R. A. Mittelstaedt, and R. H. Heflich, "Using ФX174 DNA as an exogenous reference for measuring mitochondrial DNA copy number," BioTechniques, vol. 47, no. 4, pp. 867-869, 2009.

[23] K. J. Livak and T. D. Schmittgen, "Analysis of relative gene expression data using real-time quantitative PCR and the 2$\Delta \Delta$ CT method," Methods, vol. 25, no. 4, pp. 402-408, 2001.

[24] S. Matsushita, K. Yoshimura, T. Kimura et al., "Spontaneous recovery of hemoglobin and neutrophil levels in Japanese patients on a long-term Combivir@ containing regimen," Journal of Clinical Virology, vol. 33, no. 3, pp. 188-193, 2005.

[25] D. Mildvan, T. Creagh, and G. Leitz, "Prevalence of anemia and correlation with biomarkers and specific antiretroviral regimens in 9690 human immunodeficiency virus-infected patients: findings of the Anemia Prevalence Study," Current Medical Research and Opinion, vol. 23, no. 2, pp. 343-355, 2007.

[26] M. I. Luster, G. J. Rosenthal, W. Cao et al., "Experimental studies of the hematologic and immune system toxicity of nucleoside derivatives used against HIV infection," International Journal of Immunopharmacology, vol. 13, supplement 1, pp. 99-107, 1991.

[27] M. B. Thompson, J. K. Dunnick, M. E. Sutphin, H. D. Giles, R. D. Irwin, and J. D. Prejean, "Hematologic toxicity of AZT and $\mathrm{ddC}$ administered as single agents and in combination to rats and mice," Fundamental and Applied Toxicology, vol. 17, no. 1, pp. 159-176, 1991.

[28] National Institute of Environmental Health Sciences, "NIEHS technical report on the 13-week toxicity study of 3' -Azido-3' deoxythymidine (AZT) and Isoniazid combinations administered by gavage to $\mathrm{B} \mathrm{C} 3 \mathrm{~F}_{1}$ mice," NIEHS AIDS Therapeutics Toxicity Report no. 8, U.S. Department of Health and Human Services, Public Health Service, National Institutes of Health Research, Triangle Park, NC, USA, 2002.

[29] M. Laguno, A. Milinkovic, E. De Lazzari et al., "Incidence and risk factors for mitochondrial toxicity in treated HIV/HCVcoinfected patients," Antiviral Therapy, vol. 10, no. 3, pp. 423429, 2005.

[30] J. A. Dykens, J. Jamieson, L. Marroquin, S. Nadanaciva, P. A. Billis, and Y. Will, "Biguanide-induced mitochondrial dysfunction yields increased lactate production and cytotoxicity of aerobically-poised HepG2 cells and human hepatocytes in vitro," Toxicology and Applied Pharmacology, vol. 233, no. 2, pp. 203-210, 2008.

[31] M. C. Wei, W. X. Zong, E. H. Y. Cheng et al., "Proapoptotic BAX and BAK: a requisite gateway to mitochondrial dysfunction and death," Science, vol. 292, no. 5517, pp. 727-730, 2001.

[32] E. Y. Tan, L. Campo, C. Han et al., "BNIP3 as a progression marker in primary human breast cancer opposing functions in in situ versus invasive cancer," Clinical Cancer Research, vol. 13, no. 2, pp. 467-474, 2007.

[33] J. L. Fang and F. A. Beland, "Long-term exposure to zidovudine delays cell cycle progression, induces apoptosis, and decreases telomerase activity in human hepatocytes," Toxicological Sciences, vol. 111, no. 1, pp. 120-130, 2009.

[34] D. J. Hooker and C. L. Cherry, "Apoptosis: a clinically useful measure of antiretroviral drug toxicity? Apoptosis: a clinically useful measure of antiretroviral drug toxicity? Hooker \& Cherry," Expert Opinion on Drug Metabolism and Toxicology, vol. 5, no. 12, pp. 1543-1553, 2009.

[35] L. Day, C. Shikuma, and M. Gerschenson, "Mitochondrial injury in the pathogenesis of antiretroviral-induced hepatic steatosis and lactic acidemia," Mitochondrion, vol. 4, no. 2-3, pp. 95-109, 2004. 


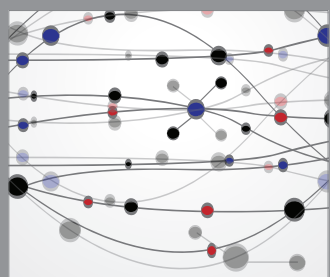

The Scientific World Journal
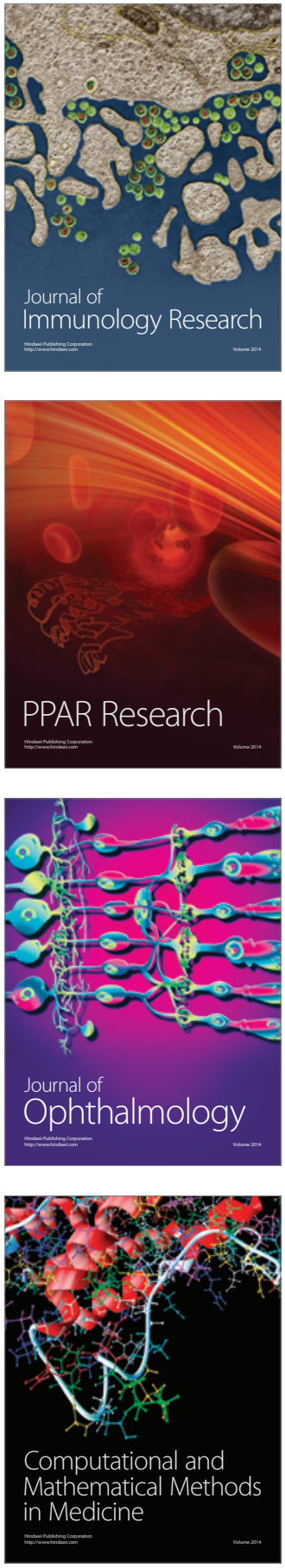

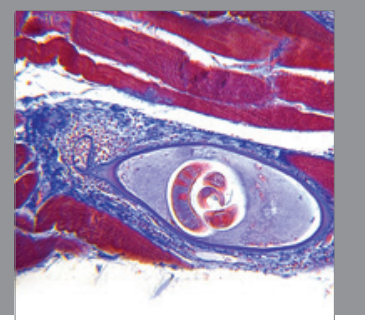

Gastroenterology

Research and Practice
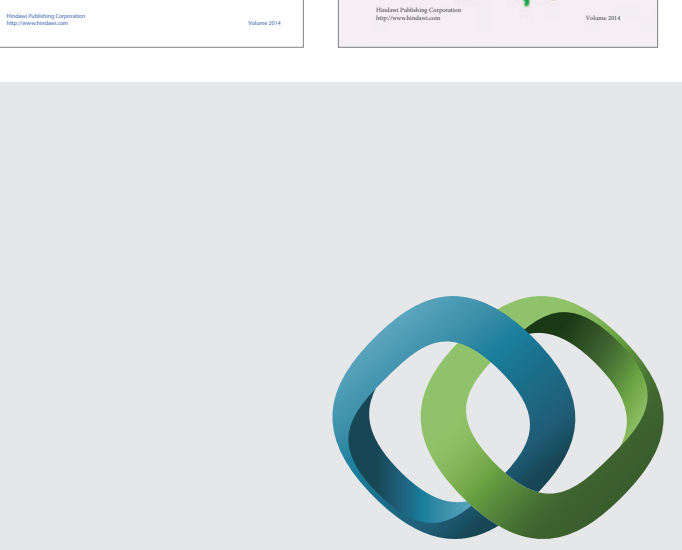

\section{Hindawi}

Submit your manuscripts at

http://www.hindawi.com
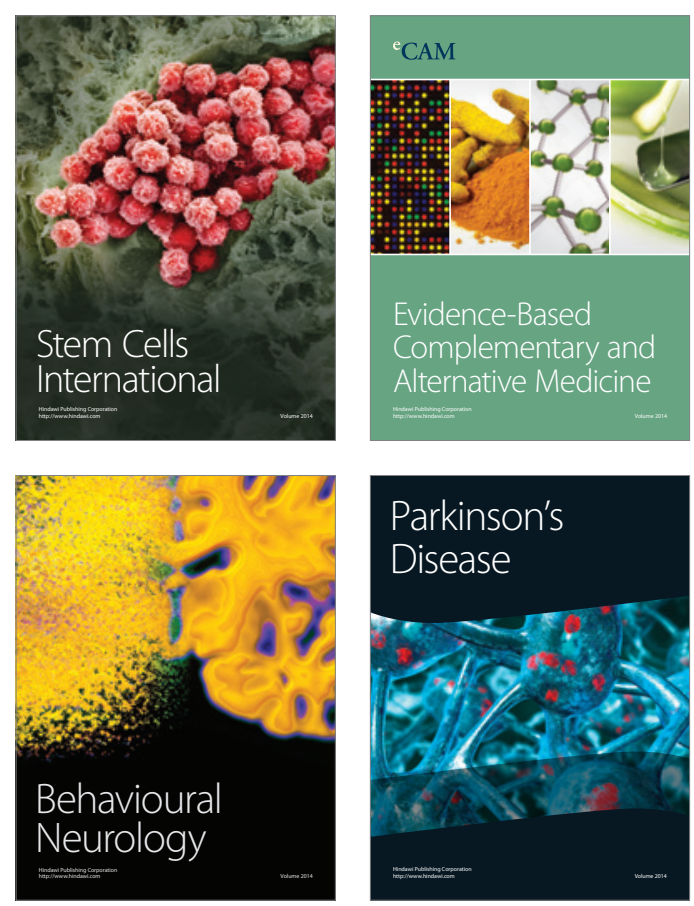

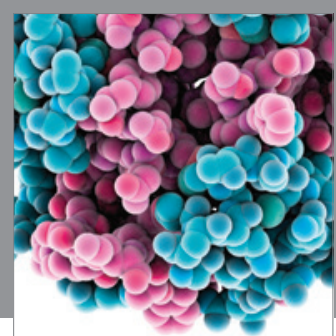

Journal of
Diabetes Research

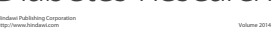

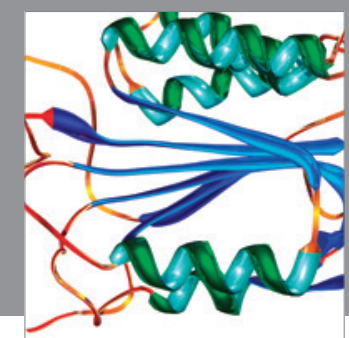

Disease Markers
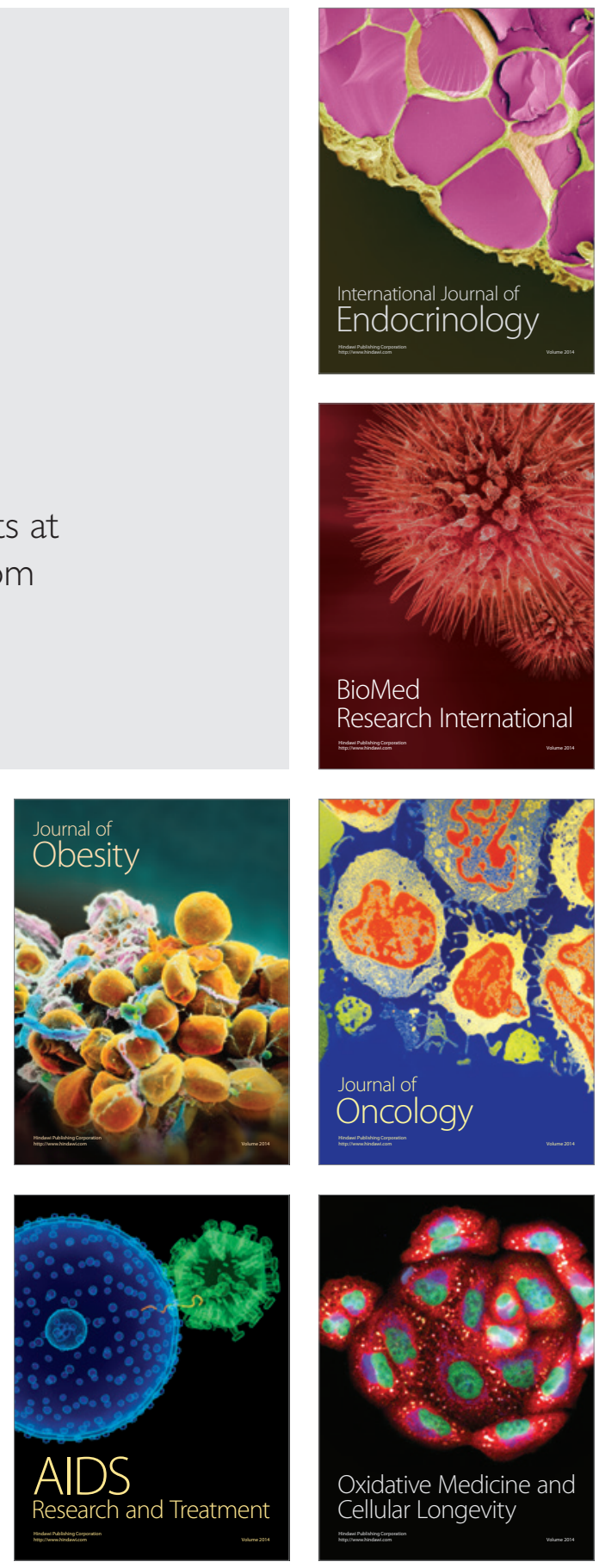